\title{
Investigation of Optimal Seismic Design Methodology for Piping Systems Supported by Elasto-plastic Dampers
}

\author{
(Part 2: Applicability for Seismic Waves with Various \\ Frequency Characteristics)*
}

\author{
Tomohiro ITO**, Masashi MICHIUE*** and Katsuhisa FUJITA**** \\ ${ }^{* *}$ Mechanical Engineering, Graduate School of Engineering, Osaka Prefecture \\ University 1-1 Gakuen-cho, Naka-ku, Sakai City, Osaka Pref. 599-8531, Japan \\ E-mail: tom.ito@me.osakafu-u.ac.jp \\ **Kawasaki Heavy Industries Ltd. 1-1 Kawasaki-cho, Akashi City, Hyogo Pref. 673-8666, Japan \\ ${ }^{* * * *}$ Graduate School of Engineering, Osaka City University, 3-3-138 Sugimoto, \\ Sumiyoshi-ku, Osaka City, Osaka Pref., 558-8585, Japan
}

\begin{abstract}
In this study, the applicability of a previously developed optimal seismic design methodology, which can consider the structural integrity of not only piping systems but also elasto-plastic supporting devices, is studied for seismic waves with various frequency characteristics. This methodology employs a genetic algorithm and can search the optimal conditions such as the supporting location and the capacity and stiffness of the supporting devices. Here, a lead extrusion damper is treated as a typical elasto-plastic damper. Numerical simulations are performed using a simple piping system model. As a result, it is shown that the proposed optimal seismic design methodology is applicable to the seismic design of piping systems subjected to seismic waves with various frequency characteristics. The mechanism of optimization is also clarified.
\end{abstract}

Key words: Optimal Seismic Design, Piping Systems, Genetic Algorithm, Seismic Waves with Various Frequency Characteristics

\section{Introduction}

Numerous piping systems are found in industrial plants, and it is very important to maintain the structural integrity of these piping systems when they are subjected to seismic excitations. In general, these piping systems are supported by numerous supporting devices in order to reduce seismic responses. Recently, in order to reduce the plant construction cost, various types of high damping supports called elasto-plastic dampers, that exhibit strong nonlinearities have been developed and applied to large scale piping systems[1]-[5]. These elasto-plastic dampers are designed to effectively absorb the vibration energy. However, the energy absorption may cause fatigue or a temperature increase in the elasto-plastic dampers [1]. In the worst case, the excessive energy absorption may cause the loss of support functions due to the failure or melting of the device materials, thereby leading to the failure in piping systems. Therefore, in the seismic design of the piping 
systems supported by elasto-plastic dampers, it is very important to consider the structural integrity of not only piping systems but also supporting devices.

In the previous studies [5], [7], we developed the optimal seismic design methodology that can consider the structural integrity of not only piping systems but also elasto-plastic supporting devices. This methodology employs a genetic algorithm and can search the optimal conditions such as the supporting location and the capacity and stiffness of supporting devices. A lead extrusion damper was treated as a typical elasto-plastic damper. Four types of evaluation functions were considered, and the effectiveness was discussed using a cantilever piping system.

In this study, using the optimal seismic design methodology proposed in the previous study, we conducted numerical simulations for an L-shaped simple piping system. In these simulations, various types of seismic waves with various frequency characteristics were employed, including various types of sinusoidal waves. The optimization behavior was investigated for the support location and the damper capacity. From the result, it is shown that the present optimal seismic design methodology is applicable to the seismic design of piping systems subjected to various types of seismic inputs with various frequency characteristics.

\section{Optimization Algorithm}

Genetic algorithm (GA) is employed as an optimization algorithm [6]. In the GA, searching points are called individuals, and they have genes that have some information on the parameters. In this study, we let genes have information on the supporting location and the capacity of supporting devices. The selection method is based on the roulette rule and elite preserving strategy. The two-point crossover method and one-point mutation method are employed. When the best individual of the present generation has the same genes as that of the previous generation, the mutation rate is set as $100 \%$ in order to prevent the best individual converging to a localized solution. The flowchart of the gene manipulation on GA is shown in Fig.1.

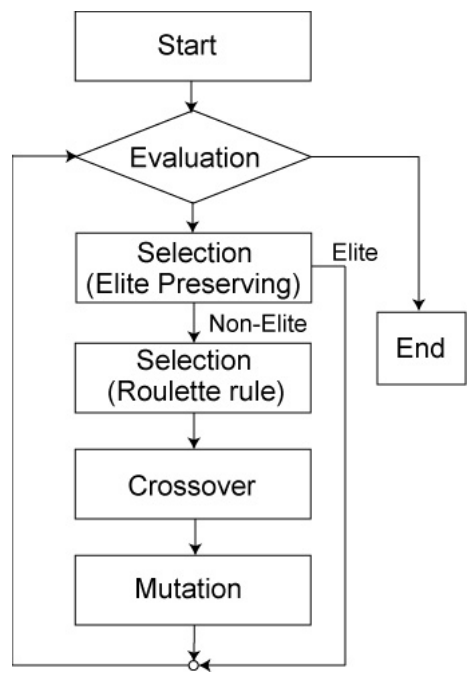

Figure 1 Flowchart of gene manipulation in GA

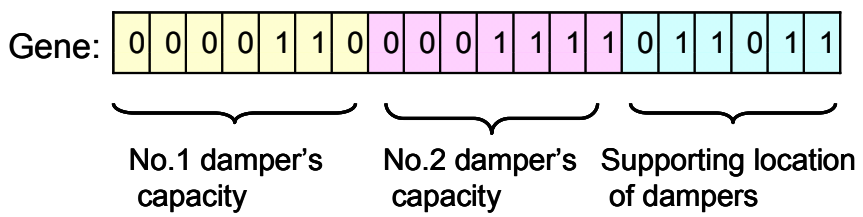

Figure 2 Relationship between structural parameters and genes 
In the present analysis, we aim to optimize the supporting location and the capacity of the dampers. Thus, these parameters are expressed as genes as shown in Fig. 2. After gene manipulation, the genes are converted into structural parameters for numerical simulations.

\section{Analytical Model and Equation of Motion}

In the previous study, we employed a cantilever piping model. In this study, in order to evaluate the piping stress caused by the torsional moment, bending moment, and shear force, an L-shaped piping system is treated as an analytical model, as shown in Fig. 3. This model is considered to be closely related to the actual piping system. The piping system is expressed by beam elements. Further, a lead extrusion damper (LED) is adopted as a typical elasto-plastic damper, similar to the previous study. The force-displacement relationship of the LED is expressed by a bilinear model, as shown in Fig. 4. The first and second stiffness, $k_{1 \mathrm{st}}$ and $k_{2 \mathrm{nd}}$, respectively, of an elasto-plastic damper are kept constant by considering the hysteretic curve of the LED. Additionally, the capacity of the elasto-plastic damper $F_{\mathrm{y}}$ is chosen as a parameter. The maximum number of elasto-plastic dampers installed on the piping system is set to two.

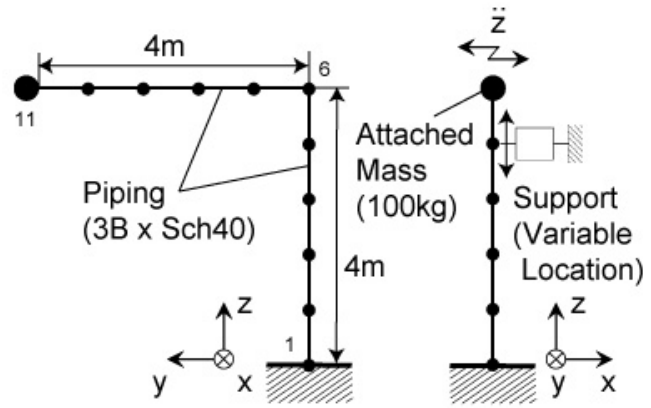

Figure 3 Analytical model of an L-shaped piping system

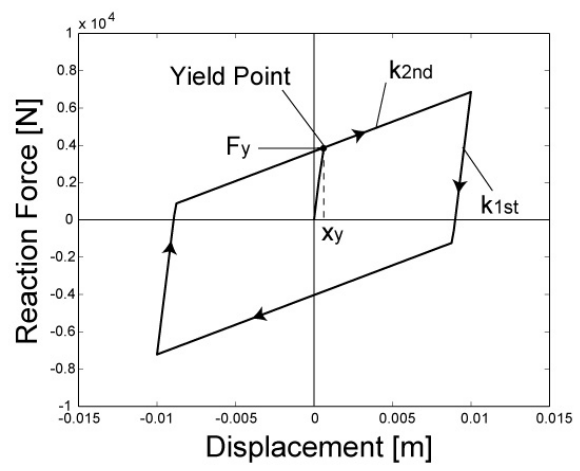

Figure 4 Bilinear model for elasto-plastic damper

The equation of motion of the analytical model is expressed by Eq. (1), where $\{x\}$ is the displacement vector, $[M]$ is the mass matrix, $[C]$ is the damping matrix, $[K]$ is the stiffness matrix, and $\{\ddot{z}\}$ is the input seismic acceleration vector. $\{F(x, \dot{x})\}$ is the reaction force vector, and it has strong nonlinear force components depending on $x, \dot{x}$. Further, the damping matrix is defined as Rayleigh's damping; which is given as $[C]=\alpha[M]$ $+\beta[K]$, where $\alpha$ and $\beta$ are constants.

$$
[M]\{\ddot{x}\}+[C]\{\dot{x}\}+[K]\{x\}=-[M]\{\ddot{z}\}-\{F(x, \dot{x})\} .
$$

The energy balance equation can be obtained by multiplying each term of Eq.(1) from 
the left side by $d x$ and integrating them for the earthquake excitation duration $t_{e}$ as shown

in Eq. (2). Using this equation, we can calculate the kinetic energy, dissipated energy, strain energy of piping systems, seismic input energy $E_{\text {in }}$ and absorbed energy by the dampers $E_{\mathrm{ab}}$.

$$
\begin{gathered}
\int_{0}^{t_{e}}\{\dot{x}\}^{T}[M]\{\ddot{x}\} d t+\int_{0}^{t_{e}}\{\dot{x}\}^{T}[C]\{\dot{x}\} d t+\int_{0}^{t_{e}}\{\dot{x}\}^{T}[K]\{x\} d t \\
=-\int_{0}^{t_{e}}\{\dot{x}\}^{T}[M]\{\ddot{z}\} d t-\int_{0}^{t_{e}}\{\dot{x}\}^{T}\{F(x, \dot{x})\} d t .
\end{gathered}
$$

\section{Evaluation Function}

Similar to the previous study[6], four types of evaluation functions are considered (a) stress on the piping systems, (b) melting of lead, (c) energy absorption, and (d) energy absorbing balance between the lead extrusion dampers.

\subsection{Evaluation of Stress on Piping Systems}

The integrity of the piping systems is evaluated by the maximum stress during the seismic excitation. The evaluation function for the stress on the piping systems, $J_{\text {stress }}$, is defined as the ratio between the maximum stress $\sigma_{\max }$ and the allowable stress $\sigma_{\text {al }}$ (here, 215 Mpa, proof stress of a high-pressure carbon steel pipe STPG370, is employed).

$$
J_{\text {stress }}= \begin{cases}\left(\sigma_{\max } / \sigma_{\mathrm{al}}\right)^{2} & \left(\sigma_{\max }<\sigma_{\mathrm{al}}\right) \\ 1000 \times\left(\sigma_{\max } / \sigma_{\mathrm{al}}\right)^{2} & \left(\sigma_{\max } \geq \sigma_{\mathrm{al}}\right) .\end{cases}
$$

\subsection{Evaluation of Energy Absorption}

The larger the energy absorption ratio $E_{\mathrm{ab}} / E_{\mathrm{in}}$, the smaller the piping system's response, where $E_{\mathrm{ab}}$ is the absorbed energy and $E_{\mathrm{in}}$ is the seismic input energy. Thus, the ratio of the total energy absorption of each damper $\Sigma E_{\mathrm{ab}}$ to the seismic input energy will be maximized. The evaluation function for the energy absorption by elasto-plastic dampers, $J_{\text {energy, }}$ is defined on the basis of the abovementioned ratio.

$$
J_{\text {energy }}=\left(1-\sum E_{\mathrm{ab}} / E_{\mathrm{in}}\right)^{2} \text {. }
$$

\subsection{Evaluation of Lead Melt of Dampers}

The LED absorbs vibration energy by utilizing the plastic deformation of lead. Thus, if this absorbed energy $E_{\mathrm{ab}}$ exceeds the allowable energy $E_{\mathrm{al}}$, the LED will lose the support functions and consequently, the failure of the piping systems will occur. Therefore, the evaluation function $J_{\text {support }}$ for the melting of lead in the dampers is defined by considering $E_{\mathrm{ab}}$ and $E_{\mathrm{al} .}$. Here, $E_{\mathrm{al}}$ is evaluated by considering the volume and heat capacity of the lead inside the LED. In this study, $E_{\mathrm{al}}$ is given by $3.4 \times F_{\mathrm{y}}$.

$$
\begin{aligned}
& J_{\text {support }}= \begin{cases}0 & \left(E_{\mathrm{ab}}<E_{\mathrm{al}}\right) \\
1000 & \left(E_{\mathrm{ab}} \geq E_{\mathrm{al}}\right) .\end{cases} \\
& E_{\mathrm{al}}=3.4 \times F_{\mathrm{y} .}
\end{aligned}
$$

\subsection{Evaluation of Energy Absorbing Balance}

In order to avoid the concentration of energy absorption in a particular elasto-plastic damper, the balance in energy absorption is considered. The evaluation function $J_{\text {balance }}$ is defined by the difference in the absorbed energy of each damper. $J_{\text {balance }}$ will be set to 0 in the case where the supporting device is not an elasto-plastic damper but a linear spring. 


$$
J_{\text {balance }}=\left|\frac{E_{\mathrm{ab} 1}}{E_{\mathrm{all}}}-\frac{E_{\mathrm{ab} 2}}{E_{\mathrm{al} 2}}\right|^{2}
$$

\subsection{Fitness Value}

In the previous study, it was found that the sum of all the four evaluation functions gives us the most reliable seismic design. Therefore, the fitness value $f$, which is the inverse value of the evaluation function $J$, is defined by Eqs. (8) and (9).

$$
\begin{aligned}
& J=J_{\text {stress }}+J_{\text {energy }}+J_{\text {support }}+J_{\text {balance }} . \\
& f=1 / J
\end{aligned}
$$

\section{Simulation Conditions}

\subsection{Dimensions of Parameters}

The parameters of optimization algorithm employed here are the same as those used in the previous study, i.e., the length of gene $l_{G}$ is 20 bits; the population size $N, 20$; the rate of selected elite individuals $P_{\text {elite }}, 0.2$; the crossover rate $P_{\text {crossover }}, 1$; the mutation rate $P_{\text {mutation}}$, $1 / Z(Z<N)$ or $1 / N(Z \geq N)$; and the maximum generation $Z_{e}, 50$. In the analytical model,

the length, the diameter, the cross section area, Young's modulus, the modulus of elasticity in shear, the moment of inertia and the density of the beam elements are $l=0.8 \mathrm{~m}, d=89.1$ $\mathrm{mm}, A=1.445 \times 10^{-3} \mathrm{~m}^{2}, E=192 \mathrm{GPa}, G=73.88 \mathrm{GPa}, I=1.267 \times 10^{-6} \mathrm{~m}^{4}$, and $\rho=7850$ $\mathrm{kg} / \mathrm{m}^{3}$, respectively. The mass and the moment of inertia of the attached mass are $M_{\text {mass }}=$ $100 \mathrm{~kg}$ and $I_{\text {mass }}=0.94 \mathrm{~kg} \cdot \mathrm{m}^{2}$, respectively. Further, the ending time of the earthquake excitation is $t_{\mathrm{e}}=30 \mathrm{~s}$. In this study, in order to simplify the evaluation, the first and second stiffness of the damper are kept constant as $k_{1 s t}=6817 \mathrm{kN} / \mathrm{m}$ and $k_{2 n d}=316 \mathrm{kN} / \mathrm{m}$, respectively considering the actual damper dimensions. The first and second natural frequencies without dampers become $f_{\mathrm{n} 1}=0.64 \mathrm{~Hz}$ and $f_{\mathrm{n} 2}=3.59 \mathrm{~Hz}$, respectively, and the damping ratios without dampers are assumed to be $\zeta_{1}=\zeta_{2}=0.008$.

\subsection{Input Seismic Waves}

In this study, four types of seismic waves that have different frequency characteristics are used as input seismic waves.

JMA Kobe-NS is the north-south component of a seismic wave recorded in the Hyogo-ken Nambu earthquake at Kobe Marine Meteorological Observatory (JMA Kobe). The time history is shown in Fig. 5. The maximum acceleration is $820 \mathrm{Gal}$ and the predominant period is around $0.35 \mathrm{~s}(2.85 \mathrm{~Hz})$, as shown in Fig. 9. This figure shows absolute acceleration response spectra of various seismic waves.

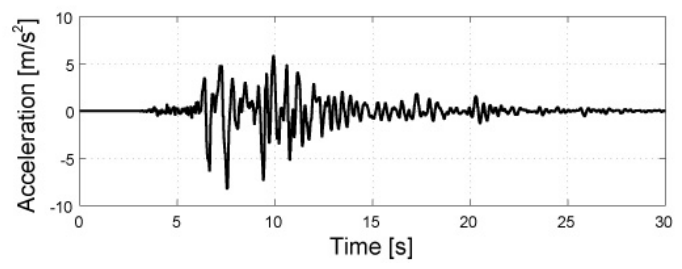

Figure 5 JMA Kobe-NS 
Tokamachi-NS is the north-south component of a seismic wave recorded in the Niigata-ken Chuetsu earthquake at Tokamachi city. The time history is shown in Fig. 6. The maximum acceleration is $1720 \mathrm{Gal}$ and the predominant period is around $0.22 \mathrm{~s}(4.52 \mathrm{~Hz})$ as shown in Fig. 9.

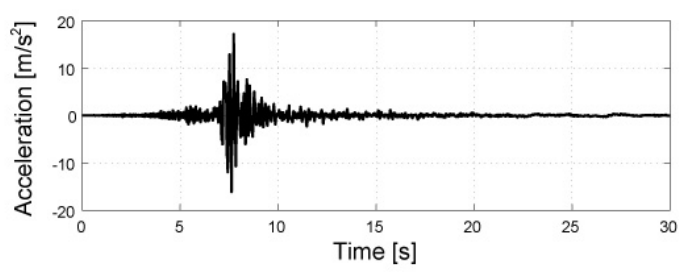

Figure 6 Tokamachi-NS

Simulated wave A is obtained from Ohsaki's spectrum with a magnitude of 8 on the Richter scale and an epicenter distance of $5 \mathrm{~km}$. The time history is shown in Fig. 7. The maximum acceleration is set to $711 \mathrm{Gal}$ and the predominant period is around $0.61 \mathrm{~s}(1.64$ Hz) as shown in Fig. 9.

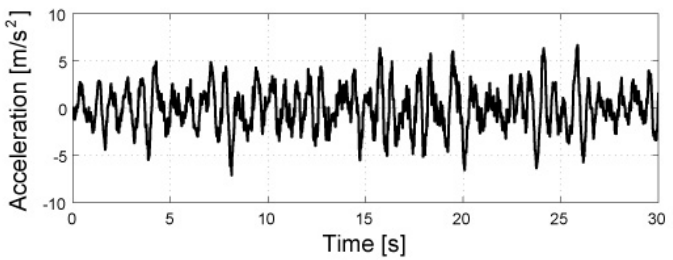

Figure 7 Simulated wave A

White noise is a time-homogeneous random noise. In this study, white noise is employed as a typical seismic input wave with broad frequency spectrum characteristics, i.e., with no predominant frequency component. Numerical studies are performed as a deterministic approach, but not as a stochastic approach such as the ones based on the Fokker-Planck equation. The time history is shown in Fig. 8. The maximum acceleration is set to $715 \mathrm{Gal}$ and no predominant period is observed as shown in Fig. 9.

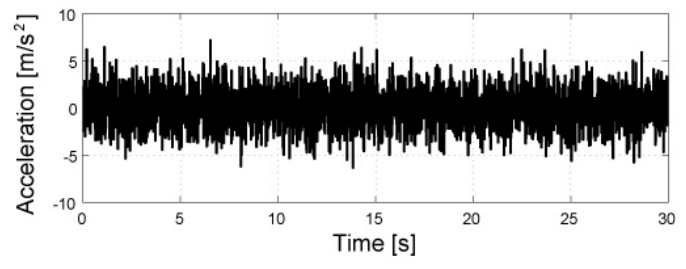

Figure 8 White noise

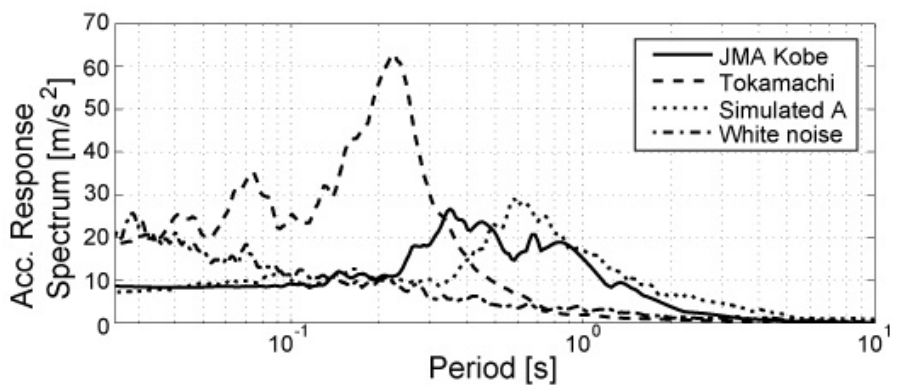

Figure 9 Acc. response spectra of various seismic waves (5\% damping ratio) 


\section{Simulation Results}

Simulation results for various seismic wave inputs are shown in Figs. 10-13 and are discussed below.

\subsection{Case of JMA Kobe-NS}

The optimization results are shown in Fig. 10. In this figure, the upper-left figure shows the fitness values for various generations. The horizontal axis shows the generation. The solid line and the dotted line show the best individuals and the worst individuals, respectively. In the present optimization, the elite preserving strategy is employed thus, the fitness values for the best individuals simply increase. From the average fitness values, the diversity of individuals can be roughly estimated. If the average values are very close to the best values, most of the individuals have the same genes and the solution may be a local solution. In Fig. 10, the average values are far from the best values thus, the diversity of individuals is maintained.

The other four figures show the earthquake response for the best individual. The upperright figure shows the vibration mode. It is found that the displacement at the top end and the elbow of the piping system are relatively large however, the maximum stress is suppressed to $39.1 \mathrm{MPa}$, which is less than $1 / 5$ of the yield stress of $215 \mathrm{MPa}$. The middle-left figure shows the hysteretic curves of the dampers. It is found that the No.2 damper effectively works as an elasto-plastic damper. The middle-right figure illustrates the accumulated seismic input energy and the dissipated energy by the dampers. Around $90 \%$ of the input energy is dissipated by the two dampers. Further, the dissipated energy is reduced to less than the allowable limit for both dampers. The lowest figure shows the response spectrum for an input seismic wave with a damping ratio of $5 \%$. In this figure, the change in the first and second natural periods after optimization is also indicated. As the piping system treated here
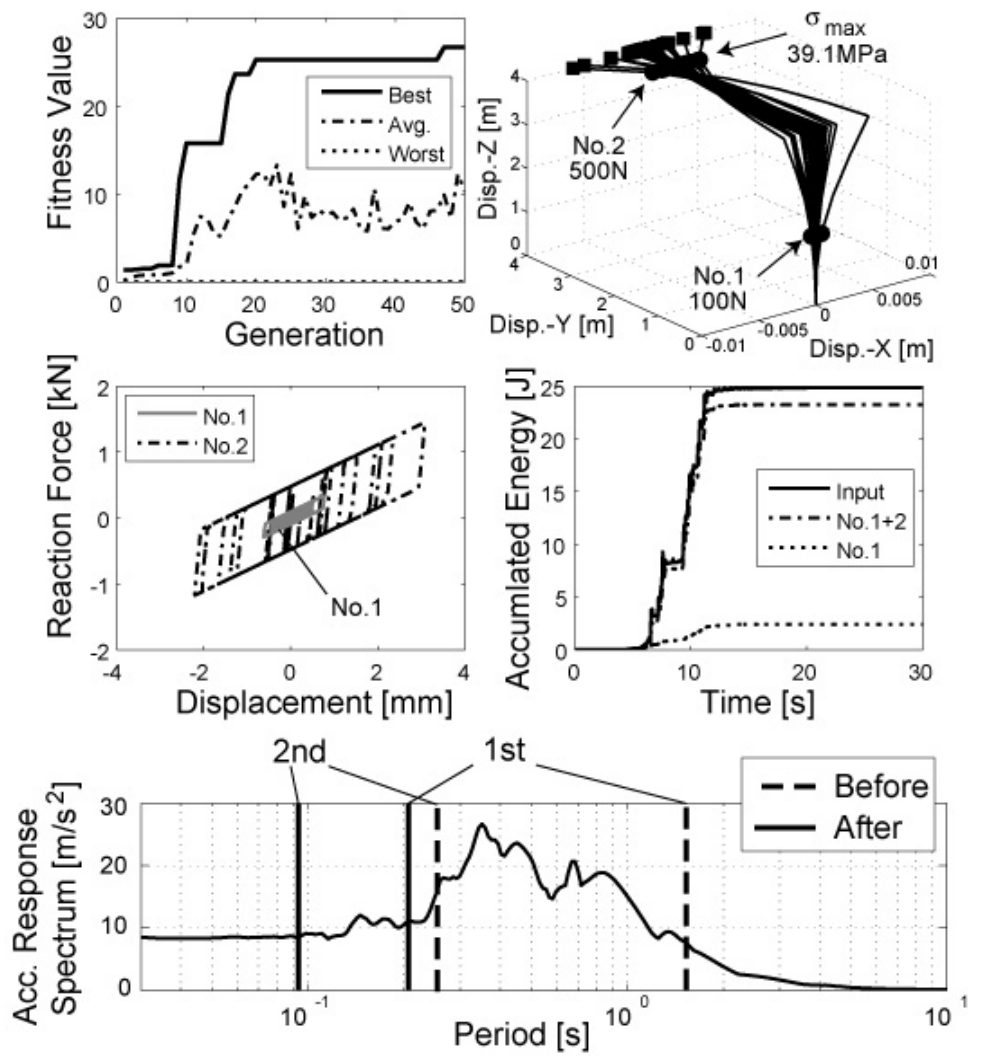

Figure 10 Optimization result: Case of JMA Kobe-NS 
is a nonlinear system, the evaluation of the natural frequencies is considered to be meaningless. However, at the beginning of seismic wave excitation, the piping system response amplitude will be so small that the elasto-plastic damper works within the elastic region. By considering these facts, we calculated the natural periods using the first stiffness of the bilinear force-displacement relationship. Throughout the present optimization, as is shown in the lowest figure, the first natural period is smaller than the predominant period of the input wave. This signifies that the optimization is accomplished by avoiding the resonance between the piping system and the seismic input wave.

\subsection{Case of Tokamachi-NS}

The optimization results are shown in Fig. 11. In this case, both dampers are settled in the region around the elbow part of the L-shaped piping system. Further, the amount of dissipated energy by each damper is almost the same. The first-mode natural period is still larger than the seismic wave peak period, while the second one becomes smaller than the predominant period of the input wave. From these results, it is noted that the present methodology can decide the optimal support location by considering the seismic wave frequency characteristics.

\subsection{Case of Simulated Wave A}

The optimization results are shown in Fig. 12. The supporting locations are very similar to those shown in Fig. 10. In this case, both the first and second natural period lines come to the left of the seismic input predominant peak, which is similar to the case of JMA Kobe-NS. These frequency changes seem to be brought based on the fact that the simulated wave A has a larger predominant period than the Tokamachi-NS wave.
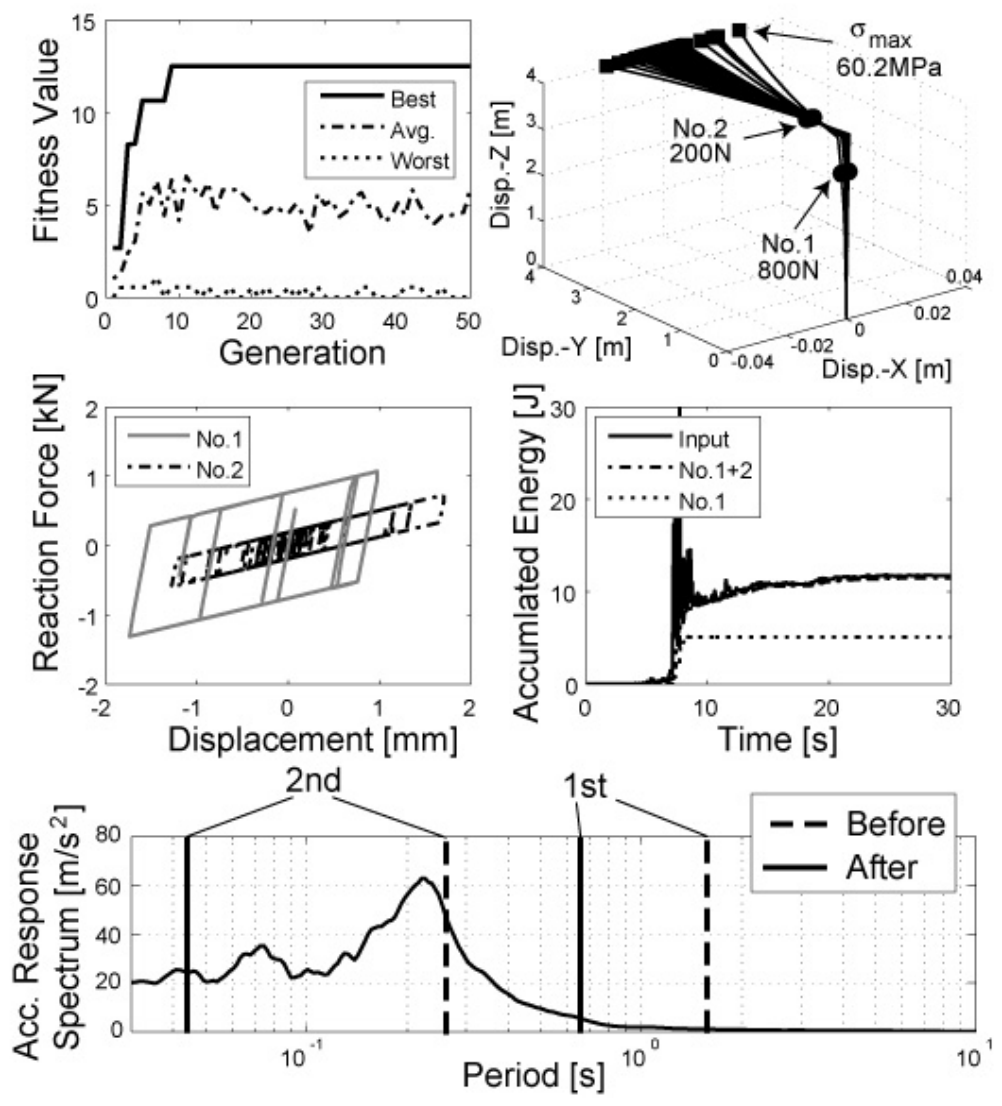

Figure 11 Optimization result: Case of Tokamachi-NS 

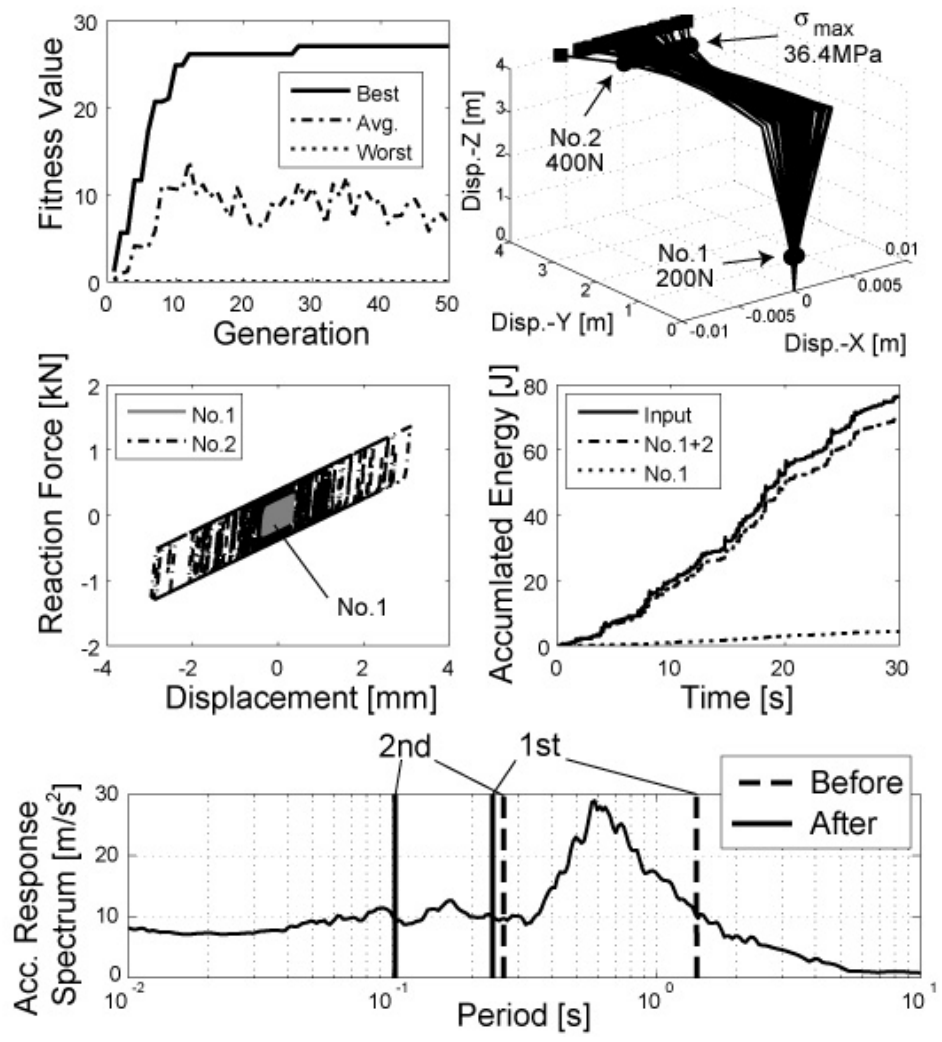

Figure 12 Optimization result: Case of simulated wave A
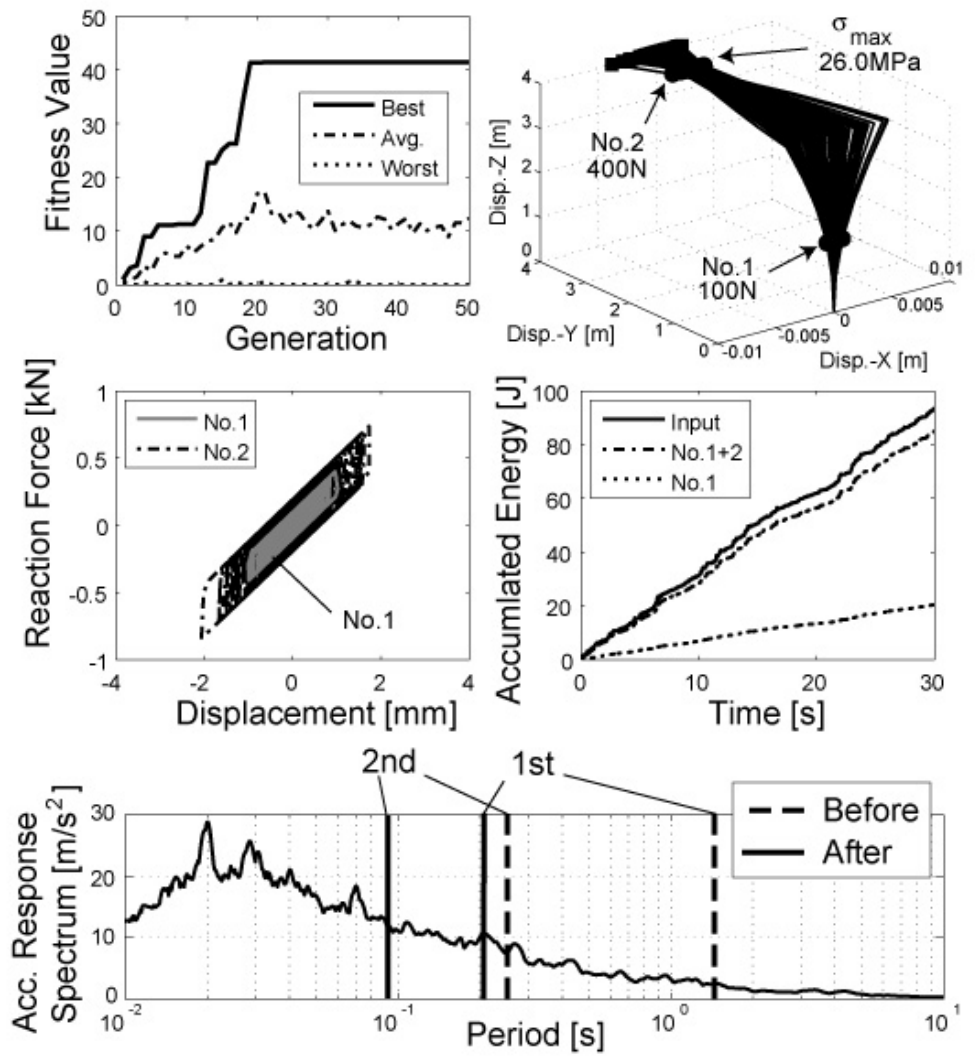

Figure 13 Optimization result: Case of white noise 


\subsection{Case of White Noise}

The results are shown in Fig. 13. As is shown in the time history in Fig. 8, the acceleration amplitude of the white noise is almost uniform during the seismic excitation, which is similar to the case of simulated wave A. Therefore, both the seismic input energy and the dissipated energy by the elasto-plastic dampers show a constant increasing rate, even at the end of the excitation. The support locations are almost the same as those in the case of JMA Kobe-NS. Further, both 2 dampers effectively work as an elasto-plastic damper. The first and second natural period lines stay on the right side of the predominant peak of the seismic wave, even after the optimization because the predominant natural period of the white noise employed here is smaller than that of other seismic waves.

\subsection{Case of Sinusoidal Wave}

In order to investigate the optimization mechanism more precisely, optimizations are performed for the sinusoidal wave inputs with various amplitudes and frequencies. The changes in the support location and yield force after the optimizations are investigated. The input acceleration is defined by Eq. (10). $a$ is varied as 300,500 and $800 \mathrm{Gals}$, and $f$ is varied as $0.6 \mathrm{~Hz}\left(=f_{\mathrm{n} 1}\right), 2 \mathrm{~Hz}, 3.6 \mathrm{~Hz}\left(=f_{\mathrm{n} 2}\right), 8 \mathrm{~Hz}$. Here, $f_{1}$ and $f_{2}$ are the first and second natural frequencies of the piping system without dampers, respectively.

$$
\ddot{z}=a \sin (2 \pi f t) .
$$

The optimization results are summarized in Tables 1-4. In these tables, the support locations and the capacity of the two dampers are shown for three types of acceleration amplitudes. If the damper stays within the elastic region, we term is as "Linear spring".

It is found that for a given excitation frequency, the support locations do not change for various excitation amplitudes. On the other hand, when the excitation frequency is changed, the support locations also change. And when the excitation amplitude is increased, the damper capacity (or yield point) also tends to increase, as shown in Table 4. The excitation frequencies and natural frequencies after optimization are summarized in Table 5. In Table 5 , it is found that in the case of $8 \mathrm{~Hz}$ excitation, the first mode natural frequency becomes $4.57 \mathrm{~Hz}$ and the second mode one becomes $13.21 \mathrm{~Hz}$, while in the other 3 cases, natural frequencies are raised more than $8 \mathrm{~Hz}$. The fundamental concept for optimization of the proposed method is to avoid resonance between the excitation wave and the piping system.

Table 1 Optimization result: $f=0.6 \mathrm{~Hz}$

\begin{tabular}{|l|l|l|}
\hline Amp:: $a$ & No.1 Support & No.2 Support \\
\hline $300 \mathrm{Gal}$ & $\begin{array}{l}\text { Node } 9 \\
\text { Linear Spring: } k_{1 \mathrm{st}}\end{array}$ & $\begin{array}{l}\text { Node } 10 \\
\text { Linear Spring: } k_{1 \mathrm{st}}\end{array}$ \\
\hline $500 \mathrm{Gal}$ & $\begin{array}{l}\text { Node } 9 \\
\text { Linear Spring: } k_{1 \mathrm{st}}\end{array}$ & $\begin{array}{l}\text { Node } 10 \\
\text { Linear Spring: } k_{1 \mathrm{st}}\end{array}$ \\
\hline $800 \mathrm{Gal}$ & $\begin{array}{l}\text { Node } 9 \\
\text { Linear Spring: } k_{1 \mathrm{st}}\end{array}$ & $\begin{array}{l}\text { Node } 10 \\
\text { Linear Spring: } k_{1 \mathrm{st}}\end{array}$ \\
\hline
\end{tabular}

Table 2 Optimization result: $f=2 \mathrm{~Hz}$

\begin{tabular}{|l|l|l|}
\hline Amp.: $a$ & No.1 Support & No.2 Support \\
\hline 300 & Node 9 & Node 10 \\
Gal & Linear Spring: $k_{1 \text { st }}$ & $F_{\mathrm{y}}=500 \mathrm{~N}$ \\
\hline \multirow{2}{*}{$500 \mathrm{Gal}$} & Node 9 & Node 10 \\
& Linear Spring: $k_{2 \text { nd }}$ & $F_{\mathrm{y}}=700 \mathrm{~N}$ \\
\hline \multirow{2}{*}{$800 \mathrm{Gal}$} & Node 9 & Node 10 \\
& $F_{\mathrm{y}}=100 \mathrm{~N}$ & $F_{\mathrm{y}}=1200 \mathrm{~N}$ \\
\hline
\end{tabular}


Table 3 Optimization result: $f=3.6 \mathrm{~Hz}$

\begin{tabular}{|l|l|l|}
\hline Amp.: $a$ & No.1 Support & No.2 Support \\
\hline \multirow{2}{*}{$300 \mathrm{Gal}$} & $\begin{array}{l}\text { Node } 9 \\
\text { Linear Spring: } k_{\mathrm{lst}}\end{array}$ & $\begin{array}{l}\text { Node } 10 \\
F_{\mathrm{y}}=400 \mathrm{~N}\end{array}$ \\
\hline \multirow{2}{*}{$500 \mathrm{Gal}$} & $\begin{array}{l}\text { Node } 9 \\
\text { Linear Spring: } k_{1 \mathrm{st}}\end{array}$ & $\begin{array}{l}\text { Node } 10 \\
F_{\mathrm{y}}=700 \mathrm{~N}\end{array}$ \\
\hline \multirow{2}{*}{$800 \mathrm{Gal}$} & $\begin{array}{l}\text { Node } 9 \\
F_{\mathrm{y}}=200 \mathrm{~N}\end{array}$ & $\begin{array}{l}\text { Node } 10 \\
F_{\mathrm{y}}=1200 \mathrm{~N}\end{array}$ \\
\hline
\end{tabular}

Table 4 Optimization result: $f=8 \mathrm{~Hz}$

\begin{tabular}{|l|l|l|}
\hline Amp.: $a$ & No.1 Support & No.2 Support \\
\hline \multirow{2}{*}{$300 \mathrm{Gal}$} & $\begin{array}{l}\text { Node } 8 \\
F_{\mathrm{y}}=400 \mathrm{~N}\end{array}$ & $\begin{array}{l}\text { Node } 9 \\
F_{\mathrm{y}}=300 \mathrm{~N}\end{array}$ \\
\hline \multirow{2}{*}{$500 \mathrm{Gal}$} & $\begin{array}{l}\text { Node } 8 \\
F_{\mathrm{y}}=800 \mathrm{~N}\end{array}$ & $\begin{array}{l}\text { Node } 9 \\
F_{\mathrm{y}}=600 \mathrm{~N}\end{array}$ \\
\hline \multirow{2}{*}{$800 \mathrm{Gal}$} & $\begin{array}{l}\text { Node } 8 \\
F_{\mathrm{y}}=1100 \mathrm{~N}\end{array}$ & $\begin{array}{l}\text { Node } 9 \\
F_{\mathrm{y}}=1000 \mathrm{~N}\end{array}$ \\
\hline
\end{tabular}

Table 5 Excitation frequencies and natural frequencies after optimization

\begin{tabular}{|c|c|c|}
\hline \multirow{2}{*}{$\begin{array}{c}\text { Excitation } \\
\text { Freq. }: f\end{array}$} & \multicolumn{2}{|c|}{ Natural Freq. } \\
\cline { 2 - 3 } & First: $f_{1}\left(T_{1}\right)$ & Second: $f_{2}\left(T_{2}\right)$ \\
\hline $0.6 \mathrm{~Hz}(1.67 \mathrm{~s})$ & $8.60 \mathrm{~Hz}(0.12 \mathrm{~s})$ & $9.84 \mathrm{~Hz}(0.10 \mathrm{~s})$ \\
\hline $2 \mathrm{~Hz}(0.5 \mathrm{~s})$ & $8.60 \mathrm{~Hz}(0.12 \mathrm{~s})$ & $9.84 \mathrm{~Hz}(0.10 \mathrm{~s})$ \\
\hline $3.6 \mathrm{~Hz}(0.28 \mathrm{~s})$ & $8.60 \mathrm{~Hz}(0.12 \mathrm{~s})$ & $9.84 \mathrm{~Hz}(0.10 \mathrm{~s})$ \\
\hline $8 \mathrm{~Hz}(0.13 \mathrm{~s})$ & $4.57 \mathrm{~Hz}(0.22 \mathrm{~s})$ & $13.21 \mathrm{~Hz}(0.08 \mathrm{~s})$ \\
\hline
\end{tabular}

In this sense, in the case of $8 \mathrm{~Hz}$ excitation, both natural frequencies should be raised furthermore than excitation frequency as well as the other 3 cases. However, in this study, the support number and its location are limited. Thus, the first mode natural frequency can not be raised furthermore than excitation frequency. Therefore, in order to avoid resonance, the first mode natural frequency is reduced far less than $8 \mathrm{~Hz}$, i.e., to $4.57 \mathrm{~Hz}$ and the second one is raised furthermore than $8 \mathrm{~Hz}$, i.e., up to $13.21 \mathrm{~Hz}$.

\subsection{Discussions}

From the results shown in Figs. 10-13, it is inferred that the support locations shown in Figs. 10, 11 and 12 are appropriate for various types of seismic waves, except for certain waves such as the Tokamachi-NS wave.

From all the results including the sinusoidal wave input results, it can be stated that in the present methodology, the optimization is achieved by adjusting the support locations, i.e., by adjusting the natural frequencies of the piping system subjected to a seismic input with some predominant frequency, and by adjusting the damper capacity for various excitation amplitudes. This means that the proposed method is effective when the characteristics of the seismic wave are known. From the view point of the actual seismic design, for very important piping systems such as those of nuclear power plants, the design seismic wave is settled at first and the detail seismic design will be performed based on this seismic wave. In this sense, this method is applicable to those important piping systems. 


\section{Conclusions}

In this study, we proposed an optimal seismic design methodology for the piping systems supported by elasto-plastic dampers. Using this methodology, optimization analyses were performed for an L-shaped piping system subjected to the seismic wave inputs and sinusoidal inputs with various amplitudes and frequency characteristics. It is confirmed that the present optimization methodology can be applied to the various types of seismic inputs stated above.

It is clarified that optimization is achieved by adjusting the supporting locations for the various types of input frequency characteristics and by adjusting the damper capacity for the various input amplitudes.

\section{References}

[1] Ito, T. and Fujita, K., 2003, "Energy Absorbing Characteristics of a High-Damping Support Utilizing Plastic Deformation of Lead and the Seismic Response Characteristics of Piping Systems", Transactions of JSME, Vol.C69, No.686, pp.2602-2609 (in Japanese).

[2] Fujita, K., et al., 1991, "Study on a Rotary Type Lead Extrusion Damper as a High Damping Support for Nuclear Piping Systems", Proc. of 11th SMiRT, Vol.K, No.33/1, pp. $475-480$.

[3] Iwatsubo,T., et al., 2002, "Seismic Proving Test of Heavy Component with Energy Absorbing Support Proving Test Results", Proc. of ASME PVP Conf., Vol.445-1, pp.107-111.

[4] Fujita, K., Kimura, T. and Ohe Y., 2004, "Seismic Response Analysis of Piping Systems With Nonlinear Supports Using Differential Algebraic Equations", Transactions of the ASME, Journal of Pressure Vessel Technology, Vol.126, pp.91-97.

[5] Ito, T., Michiue, M. and Fijita, K., 2006, "Application of Optimal Design Methodology in the Seismic Design of Piping Systems Supported by Elasto-plastic Dampers", Proc. of ASME PVP Conf., CDROM No. PVP2006-ICPVT11-93259.

[6] Ito, T., Fujita, K. and Michiue, M., 2007, "Applicability of Optimal Seismic Design Methodology for Piping Systems Subjected to Seismic Waves with Various Frequency Characteristics", Proc. of ASME PVP Conf., CDROM No. PVP2007-26436.

[7] Ito, T., Michiue, M. and Fujita, K., 2009, "Investigation of Optimal Seismic Design Methodology for Piping Systems Supported by Elasto-Plastic Dampers (Part 1: Evaluation Functions)", JSME Journal of System Design and Dynamics, Vol. 3, No.1, pp. 59-69.

[8] Goldberg, E., 1989, "Genetic Algorithms in Search, Optimization, and Machine Learning”, Addison-Wesley Pub. Co. 